\title{
BMJ Open The physical and mental health problems of refugee and migrant fathers: findings from an Australian population-based study of children and their families
}

\author{
Rebecca Giallo, ${ }^{1,2}$ Elisha Riggs, ${ }^{1,3}$ Claire Lynch, ${ }^{1}$ Dannielle Vanpraag, ${ }^{1}$ \\ Jane Yelland, ${ }^{1,3}$ Josef Szwarc, ${ }^{4}$ Philippa Duell-Piening, ${ }^{4}$ Lauren Tyrell, ${ }^{4}$ Sue Casey, ${ }^{4}$ \\ Stephanie Janne Brown ${ }^{1,2,3}$
}

To cite: Giallo R, Riggs E, Lynch C, et al. The physical and mental health problems of refugee and migrant fathers: findings from an Australian populationbased study of children and their families. BMJ Open 2017;7:e015603. doi:10.1136/ bmjopen-2016-015603

- Prepublication history for this paper is available online. To view please visit the journal online (http://dx.doi.org/10. 1136/bmjopen-2016-015603).

Received 28 December 2016 Revised 6 October 2017 Accepted 18 0ctober 2017

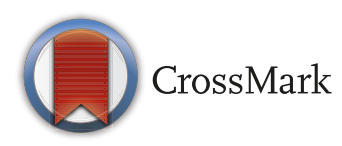

${ }^{1}$ Healthy Mothers Healthy Families Group, Murdoch Children's Research Institute, Parkville, Victoria, Australia ${ }^{2}$ Department of Paediatrics, Royal Children's Hospital, The University of Melbourne, Parkville, Victoria, Australia ${ }^{3}$ Department of General Practice and Primary Health Care Academic Centre, University of Melbourne, Carlton, Victoria, Australia

${ }^{4}$ The Victorian Foundation for Survivors of Torture, Brunswick, Australia

Correspondence to A/Prof Rebecca Giallo; rebecca.giallo@mcri.edu.au

\section{ABSTRACT}

Objectives The aim of this study was to report on the physical and mental health of migrant and refugee fathers participating in a population-based study of Australian children and their families.

Design Cross-sectional survey data drawn from a population-based longitudinal study when children were aged $4-5$ years

Setting Population-based study of Australian children and their families.

Participants 8137 fathers participated in the study when their children were aged 4-5 years. There were 131 (1.6\%) fathers of likely refugee background, 872 (10.7\%) fathers who migrated from English-speaking countries, 1005 (12.4\%) fathers who migrated from non-Englishspeaking countries and 6129 (75.3\%) Australian-born fathers.

Primary outcome measures Fathers' psychological distress was assessed using the self-report Kessler-6. Information pertaining to physical health conditions, global or overall health, alcohol and tobacco use, and body mass index status was obtained.

Results Compared with Australian-born fathers, fathers of likely refugee background (adjusted OR(aOR) 3.17, 95\% Cl 2.13 to 4.74) and fathers from non-English-speaking countries (a0R 1.79, 95\% $\mathrm{Cl} 1.51$ to 2.13 ) had higher odds of psychological distress. Refugee fathers were more likely to report fair to poor overall health $(\mathrm{aOR} 1.95,95 \% \mathrm{Cl} 1.06$ to 3.60 ) and being underweight (aOR $3.49,95 \% \mathrm{Cl} 1.57$ to 7.74) compared with Australian-born fathers. Refugee fathers and those from non-English-speaking countries were less likely to report light (aOR $0.25,95 \% \mathrm{Cl} 0.15$ to 0.43 , and aOR $0.30,95 \% \mathrm{Cl} 0.24$ to 0.37 , respectively) and moderate to harmful alcohol use (aOR $0.04,95 \% \mathrm{Cl} 0.10$ to 0.17 , and aOR $0.14,95 \% \mathrm{Cl} 0.10$ to 0.19 , respectively) than Australian-born fathers. Finally, fathers from nonEnglish-speaking and English-speaking countries were less likely to be overweight (aOR $0.62,95 \% \mathrm{Cl} 0.51$ to 0.75 , and aOR $0.84,95 \% \mathrm{Cl} 0.68$ to 1.03 , respectively) and obese (aOR $0.43,95 \% \mathrm{Cl} 0.32$ to 0.58 , and a0R 0.77 , $95 \% \mathrm{Cl} 0.61$ to 0.98 , respectively) than Australian-born fathers.

\section{Strengths and limitations of this study}

- To our knowledge, this is the first populationbased birth cohort study in a high-income country to identify and report mental and physical health outcomes for fathers of likely refugee background.

- The design of the study and size of the sample enabled us to compare mental and physical health outcomes and health behaviours in fathers of refugee background with Australian-born fathers and migrant fathers of non-English-speaking and English-speaking backgrounds.

- We used a proxy measure to ascertain refugee background. While this may have resulted in some misclassification, confirmation of refugee status is rarely possible in administrative datasets. Even when visa status is collected, it is not necessarily a reliable indicator.

- Migrant families of non-English-speaking backgrounds were under-represented in the study and were more likely to be lost to follow-up. The sample is likely to be representative of more socially and economically advantaged families with higher levels of English proficiency.

Conclusion Fathers of refugee background experience poorer mental health and poorer general health than Australian-born fathers. Fathers who have migrated from non-English-speaking countries also report greater psychological distress than Australian-born fathers. This underscores the need for primary healthcare services to tailor efforts to reduce disparities in health outcomes for refugee populations that may be vulnerable due to circumstances and sequelae of forced migration and to recognise the additional psychological stresses that may accompany fatherhood following migration from nonEnglish-speaking countries. It is important to note that refugee and migrant fathers report less alcohol use and are less likely to be overweight and obese than Australian-born fathers. 
Migration around the world is at its highest ever recorded, with 244 million individuals crossing international borders in $2015 .{ }^{1}$ While many people willingly leave their home country for education and employment opportunities, there are currently over 65 million people who have been forcibly displaced from their homes due to conflict, persecution and human rights abuse. ${ }^{2}$ Many of these displaced people will seek protection from another country as a refugee. The process of settlement and acculturation can be a time of significant stress for both migrants and refugees. Common sources of stress include learning a new language, finding employment and housing, navigating unfamiliar health and education services, and adjusting to changing family relationships. ${ }^{3-6}$ For people of refugee background, these stresses may be compounded by having endured traumatic events, such as experiencing or witnessing harm, death or threats to others; family separation; time spent in detention and refugee camps; and long periods of limited access to basic needs such as food, water, shelter and safety. ${ }^{36}$

For people of migrant and refugee background, settlement and acculturative experiences can increase the risk of physical and mental health difficulties. For instance, a meta-analysis of 35 studies reported prevalence estimates for depression and anxiety of approximately $20 \%$ among migrants and $40 \%$ among refugees. Symptoms may persist for many years post-settlement, ${ }^{78}$ leading to concerns about potential intergenerational impact within families. Internationally, there has been considerable interest in the mental health of women of refugee and migrant backgrounds during and after pregnancy. ${ }^{9}{ }^{10}$ Australian research has shown that women of refugee and migrant background are more likely to experience depressive symptoms after childbirth, compared with women born in Australia. ${ }^{11-13}$ There is also evidence that women of refugee and migrant background have higher rates of stillbirth, foetal death in utero and perinatal mortality compared with Australian-born women. ${ }^{14}$ This has also been demonstrated internationally for other high-income countries. ${ }^{15}$

Much less is known about fathers of refugee and migrant background. The focus on fathers of young children is critical given their important role in supporting their families to adjust to life in their new country ${ }^{516}$ and to the health, well-being and development of their children. ${ }^{17}$ Mental health problems such as anxiety and depression affect $10 \%-12 \%$ of fathers in the general population in the early years of parenting. ${ }^{18-22}$ Although the prevalence of mental health problems is likely to be higher among fathers of refugee or migrant backgrounds, research in this area is scarce. A study conducted almost a decade ago found that migrant fathers can feel undermined in their traditional role as the head of the household when they experience difficulty finding suitable employment. This may lead to migrant fathers feeling alienated and disrespected at a broader societal level and within their own families. ${ }^{5}$

While studies of refugee men more broadly have reported high levels of post-traumatic, depressive and anxiety symptoms, ${ }^{723-25}$ as well as musculoskeletal, respiratory, cardiovascular and infectious diseases, ${ }^{424}{ }^{26}$ few studies have focused specifically on fathers of refugee background. In a study of 29 refugee fathers, resettled in the Netherlands, $86 \%$ reported symptoms of post-traumatic stress disorder (PTSD) ${ }^{27}$ In another study of 50 refugee fathers from Vietnam, resettled in Norway, ${ }^{17}$ approximately $28 \%$ met the full or partial criteria for PTSD on arrival. Approximately 23-24 years after arrival, $15 \%$ met the full or partial criteria for PTSD, and 20\% met the clinical cut point on the General Symptom Inventory, which is indicative of a probable psychiatric disorder. No studies have reported on the physical health or health behaviours (ie, cigarette smoking, alcohol use) of refugee fathers.

Taken together, this small but important body of research suggests that fathers of migrant and refugee background might be at risk for increased mental and physical health problems. Determining the extent to which these fathers experience physical and mental health problems is critical to the development of health policy and services to better meet their needs in the critical early years of their children's lives. This is particularly important in Australia given that in 2015-2016, Australia admitted around 190000 permanent migrants (mainly for skills and labour) and over 17500 on humanitarian (mainly refugees) grounds. Furthermore, our previous research has shown that when health professionals interact with refugee fathers, they are unlikely to inquire about the health and well-being needs of men themselves, therefore missing opportunities to provide care and support. ${ }^{28}$

The objective of this paper was to investigate the mental and physical health and health behaviours of fathers of refugee and migrant backgrounds in an existing population-based sample of over 8000 Australian children (aged 4-5 years) and their families participating in the Longitudinal Study of Australian Children (LSAC). Although LSAC was not designed specifically to investigate the needs of refugee and migrant families, rich data on psychological distress, physical health problems, body mass index, alcohol use and cigarette smoking are available. We draw on the data available when children were aged $4-5$ years-a critical and formative time during early childhood. The specific aim of the current study was to compare the mental and physical health and health behaviours of refugee fathers and those who had migrated from an English-speaking and non-English-speaking country to Australian-born fathers.

\section{METHOD}

\section{Study design}

Data were drawn from two cohorts of children and their families participating in Growing up in Australia: The Longitudinal Study of Australian Children. The design and field methods have been described elsewhere. ${ }^{29-34}$ Ethics approval was obtained from the Australian Institute of Family Studies Human Research Ethics Committee 
and Australian states and territories education departments. Briefly, both cohorts were recruited in 2004. The birth cohort (B-cohort) was recruited when the children were less than 12 months of age, and the kindergarten cohort (K-cohort) was recruited when the children were aged $4-5$ years. Sampling details are outlined below. Each cohort has been followed up every 2 years. As a result, the age of the children in the two cohorts began to overlap at wave 3 when the B-cohort children were 4-5 years of age. The present study used data from the overlapping cohorts at age 4-5 (B-cohort wave 3, K-cohort wave 1). Preliminary analysis of the data failed to reveal any significant cohort effects $^{29}$; therefore, both cohorts were combined for this paper.

Sampling was based on a two-stage process. First, approximately $10 \%$ of all Australian postcodes were selected. Second, a number of children proportional to population size for each postcode were randomly selected using the Australian universal health insurance database (Medicare). There were 5107 children recruited into the B-cohort (64\% response rate) and 4983 into the K-cohort (59\% response rate). The sample was broadly representative of children and parents in the Australian population; however, there was under-representation of mothers who had not completed year 12 of their secondary education, children of non-English-speaking background and single parent families in both cohorts. ${ }^{33}$

The cohorts were reassessed every 2 years via a combination of face-to-face and computer-assisted interviews, self-complete questionnaires, direct assessment of children's functioning, time use diaries and linking to administrative data. To increase the involvement of parents from non-English-speaking backgrounds at wave 3 (B-cohort) and wave 1 (K-cohort), telephone interviews were conducted in a language other than English with 97 parents. ${ }^{32}$ Fifty-eight interviews were interpreted by a family member or friend, 31 were interpreted by an Australian Bureau of Statistics interviewer fluent in the relevant language and eight interviews were conducted using an accredited interpreter. The most common languages requiring an interpreter were Arabic, Vietnamese and Cantonese.

The sample size for the B-cohort and K-cohort when children were aged 4-5 years was 4386 and 4983 , respectively.

\section{Study sample}

The analytical sample for the current study was biological, step, adoptive or foster fathers participating in the B-cohort and K-cohort. Data collected from fathers at the overlapping cohort stage when all children were aged 4-5 years (B-cohort at wave 3 and K-cohort at wave 1 ) was used. Previous analyses revealed no significant cohort effects. $^{29}$

Country of birth was used to identify fathers who were Australian-born or born in another country. Fathers from English-speaking or predominantly non-English-speaking countries were identified using the official language of the country where they were born. To identify fathers of likely refugee background, we used country of birth and year of arrival in Australia to allow for matching to Australian migration trends. Two different methods were used depending on the father's year of arrival into Australia. From 1990, data on migration to Australia through humanitarian grounds by country of birth and year of arrival were accessed from the Australian Government's Settlement Reporting Facility. ${ }^{35}$ Likely refugee background was defined as those countries where at least two-thirds of migration from that country to Australia has been through the humanitarian stream. This approach was adopted from Gibson-Helm and colleagues ${ }^{36}$ and an expert panel from the Murdoch Children's Research Institute and the Victorian Foundation for Survivors of Torture. ${ }^{37} 38$ Prior to 1990, complete immigration information was not made accessible by the Australian Government. Therefore, the approach by Hugo ${ }^{39}$ was applied. This uses data from the Australian Bureau of Statistics 2006 Census on birthplace contribution of refugee-humanitarian migrants to ascertain those countries contributing likely refugee background populations to Australia from 1946 through to the 1990s. The composition of migrant flows changed during the study period. For example, migrants from Asian countries (eg, China, India) have overtaken those from the UK and Europe. Refugees have been drawn from a variety of countries of origin, the main recent groups being from the Middle East, Asia and Africa. This information was taken into account in the algorithm used to ascertain fathers of likely refugee background.

\section{Measures}

Mental health

Psychological distress was assessed using the Kessler-6 (K6) ${ }^{40}$ On a 5 -point scale $(0$ none of the time to 4 all or most of the time), participants rated the extent to which they experienced feeling nervous, hopeless, restless or fidgety, extremely sad, worthless and like everything was an effort in the last 4 weeks. Two well-established cut points were used to describe the level of severity of distress. The symptomatic cut point was defined as a score of $\geq 8$, indicating significant psychological distress. The clinical cut point was defined as a score of $\geq 13$, indicating probable clinical diagnosis of a mental health condition. Cronbach's alpha for the current sample was 0.88 for fathers of refugee background, 0.81 for fathers of non-English-speaking background, 0.80 for fathers who migrated from English speaking countries and 0.83 for fathers born in Australia.

\section{Physical health conditions}

Participants indicated if they had any of the following conditions: sight and hearing problems, speech problems, difficulty learning or understanding, disfigurement or deformity, head injury, difficulty breathing and chronic pain.

Global or overall health

Global or overall health was rated on a 4-point scale ranging from 1 poor to 5 excellent, which was recoded 
into a 3-point scale (1 poor to fair health, 2 good health, 3 excellenthealth) due to low frequency of responses for poor health.

\section{Alcohol use}

Participants reported on whether they drink alcohol and how much they drink a day (0 abstain, 1 occasional less than monthly, 2 light $<2$ drinks per day, 3 moderate $2-3$ drinks per day, 4 hazardous 4-6 drinks per day, 5 harmful $>6$ drinks per day). This was recoded into three groups (1 abstain to occasional, 2 light, 3 moderate to harmful), given the low frequency of responses for abstaining and occasional drinking and moderate to hazardous levels of drinking.

\section{Cigarette smoking}

Participants reported whether they smoke tobacco cigarettes and how much they smoke a day. This was dichotomised into 1 smoking at least once a day and 2 donot smoke at all/less than once a day.

\section{Body mass index (BMI) status}

Based on participant self-report of height and weight, BMI was calculated as weight/height squared and expressed as $\mathrm{kg} / \mathrm{m}^{2}$. Participants were classified as being underweight $(<18.5)$, overweight $(\geq 25.0-29.9)$, obese $(\geq 30.0)$ and within the normal range (18.5-24.9) according to current World Health Organization classification. ${ }^{41}$

\section{Sociodemographic characteristics}

Sociodemographic characteristics pertaining to fathers' age, country of birth, year of arrival in Australia, main language spoken at home, education, employment status, individual weekly gross income and number of children in the family were collected. Socioeconomic position (SEP) was rated using a derived variable from combined parental income, education and occupational prestige. ${ }^{42}$ Families with a standardised score $\leq 25^{\text {th }}$ percentile were classified as 'low' SEP, those $\geq 75^{\text {th }}$ percentile were classified as 'high' SEP and the remainder were classified as 'medium' SEP. Continuous scores were used in all adjusted analyses. Socioeconomic status was also assessed using the Index of Relative Socio-economic Disadvantage $\left(\mathrm{SEIFA}^{43}\right)$. Each participant was given an index score based on their postcode. The index is derived from levels of income, rates of unemployment and educational attainment within the postal area. The average score on the SEIFA is 1000 , with higher scores indicating higher relative advantage for an area (ie, fewer individuals with low-income and unskilled occupations) ${ }^{43}$

\section{Data analysis}

Descriptive statistics were used to summarise the sample characteristics, and the proportions of fathers reporting psychological distress (K6), physical health problems (specific health problems and overall physical health) and health behaviours (alcohol use, cigarette smoking, BMI). $\mathrm{X}^{2}$ Tests and t-tests were computed to assess for significant differences in sociodemographic characteristics between the father groups. A series of one-way between-subjects analysis of variance (ANOVA) were conducted to assess for differences in psychological distress between the father groups on the K6 continuous variable, with and without adjusting for SEP. We also conducted further analyses adjusting for SEIFA Index of Relative Socio-economic Disadvantage. Given that the results were similar, we only present the results when adjusting for SEP. Multinomial logistic regression analyses were conducted for the K6 cut points and the categorical physical health variables, with and without adjustment for SEP. In all models, Australian-born fathers was the reference category.

Missing data for all study variables were handled using multiple imputation. Twenty complete datasets were imputed using a multivariate normal model incorporating all variables in the analyses. The descriptive, ANOVA and logistic regression analyses were conducted using complete cases as well as with the total sample using multiply imputed data. Given that the analyses yielded similar results, only those using imputed data are presented here. For these analyses, we obtained pooled estimates for all proportions and model parameter estimates. All analyses were conducted using SPSS V.21.0.

\section{RESULTS}

\section{Sample characteristics}

There was a total of 9369 children and their families participating in both cohorts when they were $4-5$ years of age. Of these, $86.9 \%(n=8137)$ had a biological, adoptive, foster or step-father in the home. There were 131 (1.6\%) fathers of likely refugee background, $872(10.7 \%)$ who had migrated from a predominantly non-English-speaking country, 1005 (12.4\%) who had migrated from an English-speaking country and $6129(75.3 \%)$ born in Australia. Table 1 presents the demographic characteristics for each group. The majority of fathers in all groups were biological in a two-parent household. Approximately, $70 \%$ of fathers of refugee background came from the Middle East and Southeast Asia, while the majority of fathers of non-English-speaking background came from Southern and Central Asia, Southeast Asia, Southern and East Africa, and the Middle East. The vast majority of fathers who migrated from an English-speaking country came from Great Britain or New Zealand. The average time since arrival was longest for fathers who migrated from an English-speaking country (21.1 years), and this was significantly longer than for fathers of refugee background (15.9years) or those who had migrated from a non-English speaking country (17.3 years).

There were significant differences between the groups of fathers with respect to education, employment and socioeconomic status. The proportion of fathers who did not complete high school was significantly higher among fathers of refugee background and fathers born in Australia than fathers from English-speaking and non-English-speaking countries. The number of fathers from non-English-speaking and English-speaking countries 
Table 1 Sample characteristics for fathers of likely refugee backgrounds, fathers who had migrated from non-Englishspeaking and English-speaking countries, and fathers born in Australia

\begin{tabular}{|c|c|c|c|c|c|c|}
\hline Demographic characteristics & $\begin{array}{l}\text { Refugee } \\
(n=131)\end{array}$ & $\begin{array}{l}\text { Migrated from } \\
\text { a non-English- } \\
\text { speaking country } \\
(\mathrm{n}=872)\end{array}$ & $\begin{array}{l}\text { Migrated from an } \\
\text { English-speaking } \\
\text { country } \\
(n=1005)\end{array}$ & $\begin{array}{l}\text { Born in } \\
\text { Australia } \\
\text { ( } n=6129)\end{array}$ & F or $\chi^{2}$ & $\mathbf{P}$ \\
\hline \multicolumn{7}{|l|}{ Caregiver type, n (\%) } \\
\hline Biological father & $131(100.0 \%)$ & $865(99.2 \%)$ & $980(97.5 \%)$ & 5967 (97.4\%) & & \\
\hline Adoptive father & $0(0.0 \%)$ & $0(0.0 \%)$ & $1(0.1 \%)$ & $12(0.2 \%)$ & 16.0 & 0.192 \\
\hline Step-father & $0(0.0 \%)$ & $7(0.8 \%)$ & $24(2.4 \%)$ & $147(2.4 \%)$ & & \\
\hline Foster father & $0(0.0 \%)$ & $0(0.0 \%)$ & $0(0.0 \%)$ & $3(<0.1 \%)$ & & \\
\hline Age (mean) & 39.3 & 39.6 & 39.4 & 37.2 & 76.4 & $<0.001$ \\
\hline \multicolumn{7}{|l|}{ Country/region of birth, $n(\%)$} \\
\hline New Zealand & $0(0.0 \%)$ & $0(0.0 \%)$ & $246(24.5 \%)$ & & & \\
\hline Great Britain & $0(0.0 \%)$ & $0(0.0 \%)$ & $553(55.0 \%)$ & & & \\
\hline North America & $0(0.0 \%)$ & $0(0.0 \%)$ & $52(5.2 \%)$ & & & \\
\hline Melanesia & $0(0.0 \%)$ & $0(0.0 \%)$ & $19(1.9 \%)$ & & & \\
\hline Polynesia & $0(0.0 \%)$ & $56(6.4 \%)$ & $11(1.1 \%)$ & & & \\
\hline Western Europe & $0(0.0 \%)$ & $62(7.1 \%)$ & $0(0.0 \%)$ & & & \\
\hline Southern Europe & $0(0.0 \%)$ & $34(3.9 \%)$ & $0(0.0 \%)$ & & & \\
\hline South Eastern Europe & $7(5.3 \%)$ & $36(4.1 \%)$ & $0(0.0 \%)$ & & & \\
\hline Eastern Europe & $1(0.8 \%)$ & $20(2.3 \%)$ & $0(0.0 \%)$ & & & \\
\hline North Africa & $8(6.1 \% 0$ & $17(1.9 \%)$ & $0(0.0 \%)$ & & & \\
\hline Middle East & 46 (35.4\%) & $84(9.6 \%)$ & $0(0.0 \%)$ & & & \\
\hline Southeast Asia & $50(38.2 \%)$ & $131(15.0 \%)$ & $0(0.0 \%)$ & & & \\
\hline Northeast Asia & $0(0.0 \%)$ & $94(10.8 \%)$ & $0(0.0 \%)$ & & & \\
\hline Southern and Central Asia & $6(4.6 \%)$ & $153(17.5 \%)$ & $0(0.0 \%)$ & & & \\
\hline South America & $5(3.8 \%)$ & $10(1.1 \%)$ & $0(0.0 \%)$ & & & \\
\hline Central America & $4(3.1 \%)$ & $1(0.1 \%)$ & $0(0.0 \%)$ & & & \\
\hline Southern and East Africa & $4(3.1 \%)$ & $90(10.3 \%)$ & $0(0.0 \%)$ & & & \\
\hline Confidentialised & $0(0.0 \%)$ & 87 (9.9\%) & $124(12.3 \%)$ & & & \\
\hline $\begin{array}{l}\text { Time since arrival in years } \\
\text { (mean) }\end{array}$ & 15.9 & 17.3 & 21.1 & & 31.2 & $<0.001$ \\
\hline $\begin{array}{l}\text { English main language spoken } \\
\text { at home }\end{array}$ & $3(2.3 \%)$ & $228(26.1 \%)$ & $925(92.0 \%)$ & $5854(95.5 \%)$ & 3882.8 & $<0.001$ \\
\hline \multicolumn{7}{|l|}{ Speaks English } \\
\hline Very well & $45(34.4 \%)$ & $450(51.6 \%)$ & $87(8.6 \%)$ & $319(5.2 \%)$ & & \\
\hline Well & $50(38.2 \%)$ & $195(22.4 \%)$ & $25(2.5 \%)$ & $20(0.3 \%)$ & & \\
\hline Not well & $30(22.9 \%)$ & $62(7.0 \%)$ & $4(0.4 \%)$ & $3(0.1 \%)$ & 192.9 & $<0.001$ \\
\hline Not at all & $2(1.5 \%)$ & $11(1.3 \%)$ & $1(0.1 \%)$ & $0(0 \%)$ & & \\
\hline Not reported/not relevant & $4(3.0 \%)$ & $154(17.7 \%)$ & $888(88.4 \%)$ & 5787 (94.4\%) & & \\
\hline \multicolumn{7}{|l|}{ High school completion } \\
\hline $\begin{array}{l}\text { Did not complete high } \\
\text { school }\end{array}$ & $55(42.0 \%)$ & $230(26.4 \%)$ & $397(39.5 \%)$ & $2884(47.1 \%)$ & 139.5 & $<0.001$ \\
\hline Completed high school & $76(58.0 \%)$ & $642(73.6 \%)$ & $608(60.5 \%)$ & 3245 (52.9\%) & & \\
\hline \multicolumn{7}{|l|}{ Tertiary education } \\
\hline No tertiary education & 97 (74.0\%) & $490(56.2 \%)$ & $653(65.0 \%)$ & 4451 (72.6\%) & 111.31 & $<0.001$ \\
\hline $\begin{array}{l}\text { Completed tertiary } \\
\text { education }\end{array}$ & $34(26.0 \%)$ & $382(43.8 \%)$ & $352(35.0 \%)$ & 1678 (27.4\%) & & \\
\hline
\end{tabular}


Table 1 Continued

\begin{tabular}{|c|c|c|c|c|c|c|}
\hline Demographic characteristics & $\begin{array}{l}\text { Refugee } \\
(n=131)\end{array}$ & $\begin{array}{l}\text { Migrated from } \\
\text { a non-English- } \\
\text { speaking country } \\
(\mathrm{n}=872)\end{array}$ & $\begin{array}{l}\text { Migrated from an } \\
\text { English-speaking } \\
\text { country } \\
(n=1005)\end{array}$ & $\begin{array}{l}\text { Born in } \\
\text { Australia } \\
\text { ( } n=6129)\end{array}$ & $\mathrm{F}$ or $\chi^{2}$ & $\mathbf{P}$ \\
\hline \multicolumn{7}{|l|}{ Employment status } \\
\hline Not in the labour force & $19(14.5 \%)$ & $44(5.0 \%)$ & $41(4.1 \%)$ & $225(3.7 \%)$ & & \\
\hline $\begin{array}{l}\text { Unemployed and looking for } \\
\text { work }\end{array}$ & $7(5.3 \%)$ & $26(3.0 \%)$ & $16(1.6 \%)$ & $87(1.4 \%)$ & 143.6 & $<0.001$ \\
\hline Part-time employment & $20(15.3 \%)$ & $72(8.3 \%)$ & $38(3.8 \%)$ & $233(3.8 \%)$ & & \\
\hline $\begin{array}{l}\text { Full-time employment } \\
\text { (30+hours/week) }\end{array}$ & $85(64.9 \%)$ & $730(83.7 \%)$ & $910(90.5 \%)$ & $5580(91.0 \%)$ & & \\
\hline \multicolumn{7}{|l|}{ Weekly income (\$A/week) } \\
\hline Less than 500 & $51(49.0 \%)$ & $171(23.4 \%)$ & $112(12.4 \%)$ & $726(11.8 \%)$ & & \\
\hline 500-999 & $32(30.8 \%)$ & $238(32.5 \%)$ & $257(28.5 \%)$ & $1828(29.8 \%)$ & & \\
\hline $1000-1999$ & $18(17.3 \%)$ & $250(34.2 \%)$ & $368(40.8 \%)$ & 2320 (37.9\%) & 197.6 & $<0.001$ \\
\hline 2000 or more & $3(2.9 \%)$ & 73 (9.9\%) & 165 (18.3\%) & 700 (11.4\%) & & \\
\hline Not reported & 27 & 140 & 103 & $555(9.1 \%)$ & & \\
\hline Study child gender, male & $57(43.5 \%)$ & $438(50.2 \%)$ & $515(51.2 \%)$ & $3145(51.3 \%)$ & 3.5 & 0.322 \\
\hline $\begin{array}{l}\text { Number of children in household } \\
\text { (mean) }\end{array}$ & 3.1 & 2.5 & 2.5 & 2.5 & 15.0 & $<0.001$ \\
\hline Two-parent household & $131(100.0 \%)$ & 868 (99.5\%) & 995 (99.0\%) & 6089 (99.3\%) & 4.7 & 0.581 \\
\hline Socioeconomic position (M, SD) & -0.64 & 0.22 & 0.24 & 0.10 & 36.9 & $<0.001$ \\
\hline \multicolumn{7}{|l|}{$\begin{array}{l}\text { Socioeconomic position } \\
\text { category }\end{array}$} \\
\hline High & $18(13.7 \%)$ & $276(31.7 \%)$ & $293(29.2 \%)$ & $1447(23.6 \%)$ & & \\
\hline Medium & $38(29.0 \%)$ & $378(43.3 \%)$ & $511(50.8 \%)$ & $3149(51.4 \%)$ & 120.2 & $<0.001$ \\
\hline Low & 75 (57.3\%) & $218(25.0 \%)$ & 201 (20.0\%) & $1533(25.0 \%)$ & & \\
\hline SEIFA disadvantage (M, SD) & 977.7 & 1018.2 & 1025.5 & 1013.9 & 28.8 & $<0.001$ \\
\hline
\end{tabular}

SEIFA, socio-economic indexes for areas.

who had completed tertiary education was higher than fathers of refugee background and fathers born in Australia. The proportion of fathers working part-time or currently unemployed was higher for fathers of refugee background and fathers from non-English-speaking countries than the other groups. Full-time employment was lower for fathers of refugee background compared with all other groups. The proportion of fathers with an average weekly income of less than $\$ 500$ was significantly higher among fathers of refugee background, and the proportion earning higher than $\$ 1000$ was lowest for this group. The proportion of fathers to have low SEP was highest among fathers of refugee background, and their SEIFA scores were significantly lower compared with the other groups. Migrant fathers (both English speaking and non-English speaking) were more likely to have high SEP compared with Australian born fathers. SEIFA scores were significantly lower for Australian-born fathers compared with both migrant father groups, and there were no significant differences between the two migrant father groups. Finally, fathers from refugee backgrounds were more likely to have larger number of children compared with all other father groups.

\section{Psychological distress}

The extent of missing data across all study variables including the $\mathrm{K} 6$ was approximately $17.6 \%$, and approximately $20 \%$ of cases had missing data. Twenty complete datasets were imputed to ensure that the number of imputations was as least as large as the percentage of missing data. ${ }^{44}$ Table 2 presents the proportion of fathers reporting psychological distress in the normal range or the symptomatic and clinical cut points. With respect to continuous scores on the K6, a one-way between-subjects ANOVA revealed significant differences in psychological distress across the groups with and without adjusting for SEP (unadjusted for SEP: $\mathrm{F}(3,8132)=34.29, \mathrm{P}<0.001$, $\eta^{2}=0.012$; adjusted for SEP; $\mathrm{F}(3,8132)=28.38, \mathrm{P}<0.001$; $\left.\eta^{2}=0.01\right)$. Tukey's post hoc tests revealed that fathers of refugee background reported significantly higher psychological distress than Australian-born fathers and fathers from English-speaking countries. Fathers migrating from 
Table 2 Descriptive statistics (unadjusted) for psychological distress measured by the Kessler-6 for each father group when their children were aged $4-5$ years

\begin{tabular}{|c|c|c|c|c|}
\hline Outcomes & $\begin{array}{l}\text { Refugee } \\
(n=131)\end{array}$ & $\begin{array}{l}\text { Migrated from } \\
\text { a non-English- } \\
\text { speaking country } \\
(\mathrm{n}=872)\end{array}$ & $\begin{array}{l}\text { Migrated from an } \\
\text { English-speaking } \\
\text { country } \\
(\mathrm{n}=1005)\end{array}$ & $\begin{array}{l}\text { Born in } \\
\text { Australia } \\
(n=6129)\end{array}$ \\
\hline Psychological distress (continuous score), mean & 9.03 & 6.4 & 5.5 & 5.2 \\
\hline \multicolumn{5}{|l|}{ Psychological distress (cut points) } \\
\hline Normal range $(<7), \mathrm{n}(\%)$ & $57(43.5 \%)$ & $554(63.5 \%)$ & $739(73.5 \%)$ & $4590(74.9 \%)$ \\
\hline Symptomatic or clinical cut point (8+), n (\%) & $74(56.5 \%)$ & $318(36.5 \%)$ & $266(26.5 \%)$ & $1539(25.1 \%)$ \\
\hline
\end{tabular}

a non-English-speaking country reported significantly higher distress than Australian-born fathers.

Table 2 indicates that the proportion of fathers reporting psychological stress at the symptomatic or clinical cut points on the $\mathrm{K} 6$ was highest for fathers of refugee background, followed by fathers from a non-English-speaking country. Table 3 indicates that without adjustment for SEP, refugee fathers had the highest odds of reporting psychological distress in the symptomatic or clinical ranges compared with fathers born in Australia. Fathers from non-English-speaking countries also had increased odds of reporting distress in the symptomatic or clinical range compared with Australian-born fathers. There were no significant differences between fathers from English-speaking countries and Australian-born fathers. These associations remained significant even when adjusting for SEP.

\section{General health and health behaviours}

Table 4 presents the proportion of fathers in each group reporting physical health conditions, global health problems, alcohol use, cigarette smoking and weight problems. The pattern of results for the multinomial logistic regression analyses with and without adjusting for SEP were similar; therefore, the adjusted results are presented in table 5 . Refugee fathers had the highest odds of fair to poor overall global health compared with fathers born in Australia. Refugee fathers and those from non-English-speaking countries had lower odds of moderate to harmful alcohol use than Australian-born fathers. Refugee fathers and those from non-English-speaking countries had higher odds of being underweight compared with Australian-born fathers. Fathers from English-speaking and non-English-speaking countries had lower odds of being overweight or obese than Australian-born fathers.

\section{DISCUSSION}

In a population-based study of over 8000 Australian families, we identified 131 fathers of likely refugee background who arrived in Australia between 1951 and 2007 from countries such as Afghanistan, Iraq, Vietnam and Cambodia. Ten percent were migrant fathers from predominantly non-English-speaking countries, and a further 12\% were migrant fathers from English-speaking countries. These proportions are somewhat under-representative of migrant families in the general Australian

Table 3 Multinomial logistic regression results examining differences in psychological distress at the Kessler-6 clinical cut point between the father groups adjusted and unadjusted for socioeconomic position when their children were aged 4-5 years

\begin{tabular}{|c|c|c|c|}
\hline Outcomes & Refugee* $^{*}$ & $\begin{array}{l}\text { Migrated from a non-English- } \\
\text { speaking country* }\end{array}$ & $\begin{array}{l}\text { Migrated from an English- } \\
\text { speaking country* }\end{array}$ \\
\hline \multicolumn{4}{|l|}{ Unadjusted for SEP } \\
\hline Normal range $(<7)$ & Ref & Ref & Ref \\
\hline $\begin{array}{l}\text { Symptomatic or clinical cut } \\
\text { point }(8+)\end{array}$ & $3.93(2.66$ to 5.81$),<0.001$ & $1.71(1.44$ to 2.03$),<0.001$ & 1.07 (0.91 to 1.27$), 0.403$ \\
\hline \multicolumn{4}{|l|}{ Mental health (K6) } \\
\hline Normal range $(<7)$ & Ref & Ref & Ref \\
\hline $\begin{array}{l}\text { Symptomatic or clinical cut } \\
\text { point }(8+)\end{array}$ & $3.17(2.13$ to 4.74$),<0.001$ & 1.79 (1.51 to 2.13$),<0.001$ & 1.13 (0.95 to 1.33$), 0.169$ \\
\hline
\end{tabular}

Bold text indicates significance at $\mathrm{P}<0.05$.

*'Fathers born in Australia' is the reference category.

K6, Kessler-6; SEP, socioeconomic position. 
Table 4 Descriptive statistics for physical health conditions for each father group when their children were aged 4-5 years

\begin{tabular}{|c|c|c|c|c|}
\hline Outcomes & $\begin{array}{l}\text { Refugee } \\
(n=131)\end{array}$ & $\begin{array}{l}\text { Migrated from } \\
\text { a non-English- } \\
\text { speaking country } \\
(\mathrm{n}=872)\end{array}$ & $\begin{array}{l}\text { Migrated from an } \\
\text { English-speaking } \\
\text { country } \\
(n=1005)\end{array}$ & $\begin{array}{l}\text { Born in } \\
\text { Australia } \\
\text { ( } n=6129)\end{array}$ \\
\hline \multicolumn{5}{|l|}{ Physical health issues } \\
\hline None & $121(92.4 \%)$ & $800(91.7 \%)$ & $913(90.8 \%)$ & $5528(90.2 \%)$ \\
\hline One or more & $10(7.6 \%)$ & $72(8.3 \%)$ & $92(9.2 \%)$ & $601(9.8 \%)$ \\
\hline \multicolumn{5}{|l|}{ Global health } \\
\hline Very good to excellent & $54(41.2 \%)$ & $452(51.8 \%)$ & $539(53.6 \%)$ & $3279(53.5 \%)$ \\
\hline Good & $45(34.4 \%)$ & $301(34.5 \%)$ & $338(33.6 \%)$ & $2089(34.1 \%)$ \\
\hline Fair to poor & $32(24.4 \%)$ & $120(13.8 \%)$ & $128(12.7 \%)$ & $761(12.4 \%)$ \\
\hline \multicolumn{5}{|l|}{ Alcohol use } \\
\hline Abstain to occasional & $84(64.1 \%)$ & $426(48.9 \%)$ & $206(20.5 \%)$ & $1277(20.8 \%)$ \\
\hline Light (<2 drinks/day) & $44(33.6 \%)$ & $380(43.6 \%)$ & $573(57.0 \%)$ & $3463(56.5 \%)$ \\
\hline $\begin{array}{l}\text { Moderate to harmful (>3 drinks/day to } \\
>6 \text { drinks/day) }\end{array}$ & $3(2.3 \%)$ & $66(7.6 \%)$ & $226(22.5 \%)$ & $1389(22.7 \%)$ \\
\hline \multicolumn{5}{|l|}{ Cigarette smoking } \\
\hline Do not smoke at all/less than once per day & $78(59.5 \%)$ & $674(77.3 \%)$ & $814(81.0 \%)$ & $4786(78.1 \%)$ \\
\hline At least once a day & $53(40.5 \%)$ & $198(22.7 \%)$ & $191(19.0 \%)$ & $1343(21.9 \%)$ \\
\hline \multicolumn{5}{|l|}{ BMI status } \\
\hline Underweight & $18(13.7 \%)$ & $60(6.9 \%)$ & $42(4.2 \%)$ & 147 (2.4\%) \\
\hline Normal weight & $41(31.3 \%)$ & $333(38.2 \%)$ & $313(31.1 \%)$ & $1675(27.3 \%)$ \\
\hline Overweight & 47 (35.9\%) & $376(43.1 \%)$ & $478(47.6 \%)$ & $3074(50.2 \%)$ \\
\hline Obese & 25 (19.1\%) & $103(11.8 \%)$ & $172(17.1 \%)$ & 1233 (20.1\%) \\
\hline
\end{tabular}

population. Australian Census data indicate that a quarter $(24.6 \%)$ of the Australian population was born overseas, and $43 \%$ had at least one overseas-born parent. ${ }^{45}$

Approximately half the fathers of likely refugee background reported high levels of psychological distress at the symptomatic and/or clinical cut points on the K6, compared with approximately a third of fathers from non-English-speaking backgrounds and approximately one quarter of those from English-speaking countries and Australian-born fathers. Fathers of likely refugee background were three to four times more likely to report psychological distress in the symptomatic and/or clinical cut points compared with Australian-born fathers. The odds were only marginally attenuated after adjusting for SEP. These findings are in line with studies reporting high rates of mental health problems for refugees ${ }^{72} 25$ and higher than the two studies reporting on post-traumatic stress symptoms of refugee fathers. ${ }^{8} 27$ We also found that fathers migrating to Australia from non-English-speaking countries were at elevated risk of psychological distress, with an almost twofold increase in odds of psychological distress in the symptomatic and/or clinical range compared with Australian-born fathers. We did not find any significant differences in psychological distress between fathers from English speaking countries and Australian-born fathers. Given that people fleeing their country to seek safety have experienced traumatic and often life-threatening events, ${ }^{3-6}$ it is not surprising that fathers of refugee background reported the highest rates of psychological distress.

Refugee fathers were also more likely to rate their general health as fair to poor and were more likely to be underweight than Australian-born fathers. Fathers from non-English-speaking countries were also more likely to be underweight than Australian-born fathers. There were no significant findings for physical health conditions such as chronic pain, sight or hearing problems, or difficulty breathing. This was somewhat surprising given that some studies of refugee men more broadly have reported that they are at increased risk for musculoskeletal, respiratory, cardiovascular and infectious diseases. ${ }^{44}{ }^{26}$ We interpret these findings with caution because, prior to 2011, refugees with disabilities were excluded from Australia's humanitarian programme, and it is possible that some fathers of refugee background were reluctant to disclose chronic health issues or disabilities. Further research into the physical health of refugee fathers is critical given that many have experienced torture and trauma and difficult prearrival experiences.

It is also important to note that refugee and migrant fathers had some protective health behaviours. For instance, refugee fathers and those from non-English-speaking countries had lower odds of light to harmful alcohol use than Australian-born fathers. 
Table 5 Multinomial logistic regression results examining differences in physical health conditions between the father groups adjusted for socioeconomic position when their children were aged 4-5 years

\begin{tabular}{|c|c|c|c|}
\hline Outcomes & Refugee* $^{*}$ & $\begin{array}{l}\text { Migrated from a non- } \\
\text { English-speaking country* }\end{array}$ & $\begin{array}{l}\text { Migrated from an English- } \\
\text { speaking country* }\end{array}$ \\
\hline \multicolumn{4}{|l|}{ Physical health conditions } \\
\hline None & Ref & Ref & Ref \\
\hline One or more & 0.59 (0.31 to 1.14$), 0.119$ & 0.85 (0.74 to 0.97 ), 0.209 & 0.97 (0.86 to 1.09 ), 0.804 \\
\hline \multicolumn{4}{|l|}{ Global health } \\
\hline Very good to excellent & Ref & Ref & Ref \\
\hline Good & 1.17 (0.71 to 1.91$), 0.540$ & 1.07 (0.86 to 1.32$), 0.557$ & 1.01 (0.85 to 1.20$), 0.939$ \\
\hline Fair to poor & 1.95 (1.06 to 3.60$), 0.033$ & 1.18 (0.88 to 1.58$), 0.264$ & 1.07 (0.80 to 1.43$), 0.639$ \\
\hline \multicolumn{4}{|l|}{ Alcohol use } \\
\hline Abstain to occasional & Ref & Ref & Ref \\
\hline Light (<2 drinks/day) & 0.25 (0.15 to 0.43$),<0.001$ & 0.30 (0.24 to 0.37$),<0.001$ & 0.97 (0.80 to 1.17 ), 0.724 \\
\hline $\begin{array}{l}\text { Moderate to harmful } \\
(>3 \text { drinks/day to }>6 \text { drinks/ } \\
\text { day) }\end{array}$ & $0.04(0.10$ to 0.17$),<0.001$ & $0.14(0.10$ to 0.19$),<0.001$ & 0.98 (0.79 to 1.22 ), 0.880 \\
\hline \multicolumn{4}{|l|}{ Cigarette smoking } \\
\hline $\begin{array}{l}\text { Do not smoke at all/less than } \\
\text { once day }\end{array}$ & Ref & Ref & Ref \\
\hline At least once a day & 1.39 (0.84 to 2.30$), 0.201$ & 1.11 (0.88 to 1.41$), 0.382$ & 0.92 (0.75 to 1.14$), 0.455$ \\
\hline \multicolumn{4}{|l|}{ Weight status } \\
\hline Normal weight & Ref & Ref & Ref \\
\hline Underweight & 3.49 (1.57 to 7.74$), 0.003$ & 2.10 (1.31 to 3.35 ), 0.003 & 1.59 (0.92 to 2.74 ), 0.095 \\
\hline Overweight & 0.60 (0.33 to 1.10$), 0.101$ & 0.62 (0.51 to 0.75$),<0.001$ & 0.84 (0.68 to 1.03$), 0.087$ \\
\hline Obese & 0.69 (0.35 to 1.36$), 0.277$ & $0.43(0.32$ to 0.58$),<0.001$ & 0.77 (0.61 to 0.98$), 0.030$ \\
\hline
\end{tabular}

Bold text indicates significance at $\mathrm{P}<0.05$.

*'Fathers born in Australia' is the reference category.

Furthermore, fathers from English-speaking countries and non-English-speaking countries had lower odds of being overweight or obese than Australian-born fathers.

Overall, the findings indicate that fathers of refugee background are more likely than Australian-born fathers to experience a range of psychological and general health issues. Migrant fathers of non-English-speaking background also appear to experience greater psychological morbidity than Australian-born fathers. While migration is likely to be a time of adjustment for all fathers born overseas, those of refugee and non-English-speaking background are more likely to experience significant stressors associated with language barriers, cultural differences and access to services that may impact on their health and well-being. Many migrants from English-speaking countries come to Australia on a 'skilled visa' with recognised qualifications and are less likely to experience difficulties finding employment and adequate income. ${ }^{46}$ This is also the case for migrants of non-English-speaking background who come to study and then remain in Australia. In contrast, fathers of refugee background may have a history of torture and other traumatic events, disrupted or limited access to education and therefore be more likely to experience prolonged periods of social and economic disadvantage after settlement. Low employment rates and low household income were observed for these fathers in our study. Understanding how these factors impact on fathers' health, well-being and family relationships is important, along with a better understanding of what factors may facilitate positive outcomes in the longer term.

\section{Strengths and limitations}

To our knowledge, this is the first population-based child cohort study in a high-income country to identify and report mental and physical health outcomes for fathers of likely refugee background. The design of the study and size of the sample enabled us to compare mental and physical health outcomes and health behaviours in fathers of refugee background with Australian-born fathers and migrant fathers of non-English-speaking and English-speaking backgrounds. In the context of increasing global economic and forced migration, it is important for public health methods to evolve in ways that permit meaningful description of population health trends. Although no information pertaining to parental or children's visa status was collected in the LSAC, by combining data on fathers' country of birth and year of arrival in Australia, we were able to identify fathers 
of likely refugee background. This method is increasingly being used as the best proxy measure of likely refugee background. ${ }^{36}{ }^{38}$ While using this approach may have led to some misclassification of fathers of refugee background in our sample, it constitutes a reasonable approximation. Furthermore, collecting information about visa status can be problematic due to sensitivities regarding disclosure and changing status over time. Hence, even when data regarding visa status are available, this information may not represent a gold standard measure.

Similar issues are apparent for identifying fathers from non-English-speaking countries. While participants were asked to report on their main language spoken at home, there was no provision made for other languages spoken at home. Accurately obtaining a picture of language spoken at home and in different contexts (ie, between parents, between parents and children, in the community, at work) is an important but complex methodological issue. We opted to use the official language(s) of the country in which the fathers were born to distinguish between fathers from English-speaking or non-English-speaking countries. This may have led to some fathers being misclassified.

Another limitation is that families of non-English-speaking backgrounds were under-represented in LSAC and were more likely to be lost to follow-up. The sample is likely to be representative of more socially and economically advantaged families with higher levels of English proficiency. This is likely to have resulted in the prevalence estimates of mental and physical health underestimating the true prevalence of poor health outcomes. Furthermore, non-English-speaking families may have declined to participate due to lack of understanding about the study and what the information would be used for. Researchers have noted that people unaccustomed to research may be fearful, concerned and worried about the information collected, who will have access to it and how it will be used. ${ }^{47-49}$ Possible solutions require working in partnership with relevant community agencies to maximise inclusion of harder to reach groups and ensuring that appropriate steps are taken to address language barriers to participation, such as the use of professional interpreters and bicultural workers. Community input through consultation and engagement can inform the development of study protocols and measures to ensure cultural appropriateness and face validity. Establishing such strategies may support retention of the cohort over time.

Another limitation is that the LSAC necessarily employed brief measures. Although the $\mathrm{K} 6$ is a widely used and psychometrically sound instrument, there has been limited assessment of its appropriateness for different cultural groups. ${ }^{50}$ Using family members to interpret may have led to under-reporting of mental and physical health problems by fathers reluctant to disclose health issues to family members. Furthermore, no information about experiences, health or well-being prior to arrival in Australia was collected for fathers born overseas. The conclusions drawn from this study must be considered within the context of these limitations.

\section{Implications and conclusions}

Internationally, it is estimated that $5 \%-10 \%$ of fathers experience mental health difficulties in the early years of their children's lives. ${ }^{1815152}$ Our findings suggest that fathers of refugee background and those who have migrated from countries with different main languages to the destination country might be particularly vulnerable to poor paternal health. These are important findings given the small but growing body of evidence demonstrating links between fathers' mental health and their children's health, wellbeing and development. ${ }^{5354}$

Building on the analyses presented in this paper, we have an opportunity to examine fathers' mental health over time and to assess longitudinally the relationship between the mental and physical health of refugee and migrant fathers and their children's health and well-being. However, we are also mindful that the picture that can be obtained from longitudinal studies needs to be supplemented by qualitative research using culturally appropriate and sensitive methods to gain in depth understanding of fathers' experiences and support needs and the longer term impacts of economic and forced migration on family functioning and well-being.

We recommend that future longitudinal studies take steps to increase the involvement of refugee and migrant families and include fathers wherever possible and appropriate. To ensure adequate representation, greater attention to methods tailored to engage and identify migrant and refugee families is essential. Overcoming barriers that limit engagement and identification of 'harder to reach' populations is critical if population studies are to be a useful vehicle for informing and tailoring services to meet the needs of increasingly diverse populations in high-income countries.

Contributors RG, ER, CL, DV, JY, JS, PD, LT, SC and SJB conceptualised the research questions and contributed to the interpretation of findings and identification of the implications. CL and DV identified fathers of likely refugee background in the Longitudinal Study of Australian Children data set using the method described. As a registered user of the longitudinal study of Australian children, $\mathrm{RG}$ accessed data and conducted all analyses and prepared tables. RG drafted the manuscript. All authors, in particular ER, JY, JS and SJB, critically revised the manuscript.

Funding This paper used data from the Longitudinal Study of Australian Children (LSAC) which was funded by Australian Government Department of Social Services. LSAC was conducted in partnership between the Department of Social Services (DSS), the Australian Institute of Family Studies (AIFS) and the Australian Bureau of Statistics (ABS). The findings reported in this article are those of the authors and should not be attributed to DSS, AIFS or the ABS. The work of the authors was supported by the National Health and Medical Research Council (NHMRC), VicHealth and the Victorian government's operational Infrastructure support programme. RG and JY are supported by NHMRC career development fellowships; and SB, by an NHMRC research fellowship.

Competing interests None declared.

Ethics approval Australian Institute of Family Studies.

Provenance and peer review Not commissioned; externally peer reviewed.

Data sharing statement The Longitudinal Study of Australian children is funded by Australian Government Department of Social Services. Data are available to registered data users. Information about data access is provided at

Open Access This is an Open Access article distributed in accordance with the Creative Commons Attribution Non Commercial (CC BY-NC 4.0) license, which 
permits others to distribute, remix, adapt, build upon this work non-commercially, and license their derivative works on different terms, provided the original work is properly cited and the use is non-commercial. See: http://creativecommons.org/ licenses/by-nc/4.0/

(c) Article author(s) (or their employer(s) unless otherwise stated in the text of the article) 2017. All rights reserved. No commercial use is permitted unless otherwise expressly granted.

\section{REFERENCES}

1. International Organization for Migration. IOM Releases global migration trends 2015 factsheet. 16, 2016. https://www.iom.int/news/ iom-releases-global-migration-trends-2015-factsheet

2. United Nations High Commissioner for Refugees. UNHCR global trends: forced displacement in 2015. Geneva, Switzerland: UNHCR, 2016.

3. Ager A, Strang A. Understanding integration: a conceptual framework. J Refug Stud 2008;21:166-91.

4. Correa-Velez I, Barnett A, Gifford S. Working for a better life: longitudinal evidence on the predictors of employment among recently arrived refugee migrant men living in Australia: International Migration, 2013.

5. Lamb ME, Bougher LD. How does migration affect mothers' and fathers' roles within their families? Reflections on some recent research. Sex Roles 2009;60:611-4.

6. Victorian Foundation for the Survivors of Torture. Rebuilding shattered lives. Melbourne, 1998.

7. Silove D, Steel Z, Bauman A, et al. Trauma, PTSD and the longerterm mental health burden amongst Vietnamese refugees : a comparison with the Australian-born population. Soc Psychiatry Psychiatr Epidemiol 2007;42:467-76.

8. Vaage AB, Thomsen PH, Silove D, et al. Long-term mental health of Vietnamese refugees in the aftermath of trauma. Br J Psychiatry 2010;196:122-5.

9. Dennis CL, Merry L, Gagnon AJ. Postpartum depression risk factors among recent refugee, asylum-seeking, non-refugee immigrant, and Canadian-born women: results from a prospective cohort study. Soc Psychiatry Psychiatr Epidemiol 2017;52:411-22.

10. Fellmeth G, Fazel M, Plugge E. Migration and perinatal mental health in women from low- and middle-income countries: a systematic review and meta-analysis. BJOG 2017;124:742-52.

11. Bandyopadhyay M, Small R, Watson LF, et al. Life with a new baby: how do immigrant and Australian-born women's experiences compare? Aust N Z J Public Health 2010;34:412-21.

12. Lansakara N, Brown SJ, Gartland D. Birth outcomes, postpartum health and primary care contacts of immigrant mothers in an Australian nulliparous pregnancy cohort study. Matern Child Health $\mathrm{J}$ 2010;14:807-16.

13. Small R, Lumley J, Yelland J. Cross-cultural experiences of maternal depression: associations and contributing factors for Vietnamese, Turkish and Filipino immigrant women in Victoria, Australia. Ethn Health 2003;8:189-206.

14. Drysdale H, Ranasinha S, Kendall A, et al. Ethnicity and the risk of late-pregnancy stillbirth. Med J Aust 2012;197:278-81.

15. Flenady V, Wojcieszek AM, Middleton $P$, et al. Stillbirths: recall to action in high-income countries.Lancet 2016;387:691-702.

16. Este DC, Tachble A. Fatherhood in the Canadian context: perceptions and experiences of Sudanese refugee men. Sex Roles 2009;60:456-66.

17. Vaage AB, Thomsen $\mathrm{PH}$, Rousseau $\mathrm{C}$, et al. Paternal predictors of the mental health of children of Vietnamese refugees. Child Adolesc Psychiatry Ment Health 2011;5:2-11.

18. Giallo R, D'Esposito F, Christensen D, et al. Father mental health during the early parenting period: results of an Australian population based longitudinal study. Soc Psychiatry Psychiatr Epidemiol 2012;47:1907-16.

19. Giallo R, D'Esposito F, Cooklin A, et al. Psychosocial risk factors associated with fathers' mental health in the postnatal period: results from a population-based study. Soc Psychiatry Psychiatr Epidemiol 2013:48:563-73.

20. Giallo R, et al. Factors associated with trajectories of psychological distress for fathers across the early parenting period: a national Australian study. Soc Psy and Psyc Epid 2014;49:1961-71.

21. Paulson JF, Bazemore SD. Prenatal and postpartum depression in fathers and its association with maternal depression: a metaanalysis. JAMA 2010;303:1961-9.

22. Leach LS, Poyser C, Cooklin AR, et al. Prevalence and course of anxiety disorders (and symptom levels) in men across the perinatal period: a systematic review. J Affect Disord 2016;190:675-86.
23. Carlsson JM, Mortensen EL, Kastrup M. Predictors of mental health and quality of life in male tortured refugees. Nord $J$ Psychiatry 2006;60:51-7.

24. Bischoff A, Schneider M, Denhaerynck K, et al. Health and ill health of asylum seekers in Switzerland: an epidemiological study. Eur J Public Health 2009;19:59-64.

25. Lie B. A 3-year follow-up study of psychosocial functioning and general symptoms in settled refugees. Acta Psychiatr Scand 2002;106:415-25.

26. Hollander AC, Bruce D, Ekberg J, et al. Longitudinal study of mortality among refugees in Sweden. Int J Epidemiol 2012:41:1153-61.

27. van Ee E, Sleijpen M, Kleber RJ, et al. Father-involvement in a refugee sample: relations between posttraumatic stress and caregiving. Fam Process 2013;52:723-35.

28. Riggs E, Yelland J, Szwarc J, et al. Fatherhood in a new country: a qualitative study exploring the experiences of afghan men and implications for health services. Birth 2016;43:86-92.

29. Australian Institute of Family Studies. Longitudinal Study of Australian Children data user guide. Melbourne: Australian Institute of Family Studies, 2011.

30. Daraganova G, Sipthorp M. Wave 4 weights (LSAC technical Paper No. 9). Melbourne: Australian Institute of Family Studies, 2011.

31. Mission S, Sipthorp M. LSAC technical paper no. 5: wave 2 weighting and non-response. Melbourne: Australian Institute of Family Studies, 2007.

32. Sipthorp M, Mission S. LSAC technical paper no. 6. wave 3 weighting and non-response. Melbourne, Australia: Australian Institute of Family Studies, 2009.

33. Soloff C, et al. LSAC technical paper no. 3: wave 1 weighting and non-response. Melbourne: Australian Institute of Family Studies, 2006.

34. Soloff C, Lawrence D, Johnstone R. LSAC technical paper, no. 1. Melbourne: Australain Institute of Family Studies, Commonwealth of Australia., 2005.

35. Australian Government. Australian government's settlement reporting facility, 2016. http://www.immi.gov.au/settlement/srf/

36. Gibson-Helm M, Boyle J, Block A, et al. Use of country of birth as an indicator of refugee background in health datasets. BMC Med Res Methodol 2014;14:27.

37. Yelland J, Riggs E, Szwarc J, et al. Bridging the gap: using an interrupted time series design to evaluate systems reform addressing refugee maternal and child health inequalities. Implement $\mathrm{Sci}$ 2015;10:62

38. Yelland J, Riggs E, Szwarc J, et al. Improving the ascertainment of refugee-background people in health datasets and health services. Aust Health Rev 2017.

39. Hugo G. Economic, social and civic contributions of first and second generation humanitarian entrants. A final report to the department of immigration and citizenship Australia: University of Adelaide, 2011

40. Kessler RC, Barker PR, Colpe LJ, et al. Screening for serious mental illness in the general population. Arch Gen Psychiatry 2003;60:184-9.

41. WHO. BMI Classifications, 2006. http://apps.who.int/bmi/index.jsp? introPage=intro_3.htm

42. Blakemore T, Strazdins L, Gibbings J. Measuring family socioeconomic position. Australian Social Policy 2009;8:121-68.

43. Trewin D. Socio-economic indexes for areas, Australia 2001, 2003.

44. White IR, Royston P, Wood AM. Multiple imputation using chained equations: issues and guidance for practice. Stat Med 2011;30:377-99

45. Australian Bureau of Statistics. 3412.0 Migration, Australia, 20142015. Canberra: Australian Bureau of Statistics, 2016.

46. Australian Bureau of Statistics. 3418.0 - Personal income of migrants, Australia, experimental, 2010-11. Canberra: Australian Bureau of Statistics, 2015.

47. Block K, Riggs E, Haslam N, eds. Ethics in research with refugees and asylum seekers: Processes, power and politics. In: Values and vulnerabilities: the ethics of research with refugees and asylum seekers. Queensland, Australia: Australian Academic Press, 2013.

48. Ellis BH, Kia-Keating M, Yusuf SA, et al. Ethical research in refugee communities and the use of community participatory methods. Transcult Psychiatry 2007;44:459-81.

49. Riggs E, Yelland J, Szwarc J, et al. Promoting the inclusion of Afghan women and men in research: reflections from research and community partners involved in implementing a 'proof of concept' project. Int J Equity Health 2015;14:13.

50. Stolk Y, Kaplan I, Szwarc J. Clinical use of the Kessler psychological distress scales with culturally diverse groups. Int J Methods Psychiatr Res 2014;23:161-83. 
51. Liu CH, Yasui M, Giallo R, et al. US Caregivers with mental health problems: parenting experiences and children's functioning. Arch Psychiatr Nurs 2016;30:753-60.

52. Paulson JF, Dauber S, Leiferman JA. Individual and combined effects of postpartum depression in mothers and fathers on parenting behavior. Pediatrics 2006;118:659-68.
53. Fletcher RJ, Feeman E, Garfield C, et al. The effects of early paternal depression on children's development. Med J Aust 2011;195:685-9.

54. Ramchandani P, Psychogiou L. Paternal psychiatric disorders and children's psychosocial development. Lancet 2009;374:646-53. 